\title{
Dourgouti Island Hotel Project: An Urban Dig Project
}

\author{
Dikaia Chatziefstathiou ${ }^{1}$, Christos Ananiadis ${ }^{2}$, George Sachinis ${ }^{3, *}$ \\ ${ }^{1}$ School of Human and Life Sciences, Canterbury Christ Church University, Canterbury, UK \\ ${ }^{2}$ Cultural Management (MSc.), Panteion University, Athens, Greece \\ ${ }^{3}$ Ohi Pezoume Performance Company, Athens, Greece
}

Copyright $@ 2018$ by authors, all rights reserved. Authors agree that this article remains permanently open access under the terms of the Creative Commons Attribution License 4.0 International License

\begin{abstract}
Dourgouti Island Hotel Project is an ongoing programme of cultural activities created by a theatre company in the historical but "forgotten" neighbourhood of Athens, Greece, called Dourgouti. These activities offer not only cultural products but also new ways of living and experiencing the city. A model of cooperation focusing on strong assets of a place can be a new model for local economy. The results of the project mentioned in this paper show the impact of culture on local society as well as some economic benefits, showing the way to a new economy, organized from the "bottom-up".
\end{abstract}

Keywords Arts, Culture, Neighbourhood, Local Community, Local Society, Urban

\section{Introduction}

Dourgouti is a neighbourhood in the southern borders of the municipality of Athens that connects the city with the port of Pireaus. Dourgouti was one of the places where the large waves of immigrants settled during the genocide of the Christian Ottoman Greek population (1919-1922). In the 1960s it was one of the last neighbourhoods of shacks in Athens that changed into Housing Blocks. Minutes away from Syngrou Ave, which is in the process of becoming Athens' "museum mile", is a neglected area rich in cultural capital, still home of migrants from Asia and Africa.

Dourgouti Island Hotel Project (2015-2016) at Dourgouti neighbourhood of Athens is a showcase for the collective cross-field research and management of local cultural capital and for activating a local community network with sustainable features. It is a showcase of the Urban Dig Project, a platform created by awarded Ohi Pezoume Performing Arts Company (TEDxAthens $1^{\text {st }}$ prize, 2011).

Ohi Pezoume Performing Arts Company specializes in urban site-specific performances, i.e. performances that are inspired by the past, present and future (aspirations) of urban areas.
The group inspires a cross-field horizontal network of scientists, artists, researchers, students, residents of all ages to research and map a neighbourhood. The backbone of the research method is the voluntary formation of:

(a) a series of community events with the double role of collecting and sharing interesting material about the neighbourhood

(b) a number of cross-field research groups created by residents, scientists, artists, University students.

Apart from the work of the research and mapping groups, other activities organized in Dourgouti included:

- $\quad$ Outdoor film screening

- $\quad$ Local festival by the residents and friends inspired by the neighbourhood [with 55 participating groups] and inspiring the neighbourhood to collect material.

- International performance workshops (here and abroad)

- Community-led historical walks and explorations

- Open air community mappings (of history and of community aspirations)

- $\quad$ Sensory mapping walks (impressions on their 5 senses of 230 visitors]

- $\quad$ Young actors performance workshop

- $\quad$ Photography \& archival material exhibition

- $\quad$ Street performances

- Collaborations with University courses presentation of student research to the community.

- Outreach presentations of neighbourhood and research results in conferences, publications and press

\section{Materials and Methods}

\subsection{Asset Mapping}

The methodology used in this project for local development resembles Asset Mapping, a method used officially by local authorities. According to McNight [1] 
there are two ways for bringing development to the community. One is to focus on needs, deficiencies or shortcomings and the other one is to focus on possibilities and available resources. It is the latter that is more effective, yet, not usually implemented.

Mapping the needs of an area defines the attitude of people regarding local development. In many deprived areas residents believe that economic development depends on top-down help from external stakeholders, and as a result they turn into service consumers. This in fact reduces the motive for production. Consumers of services spend a lot of their creative capacities in their efforts to survive by "cheating" the system. According to Fuller [2] residents of an area can easily believe that the "map of needs" is the only reality.

The alternative option is that of a development focused on capacities and resources. Even the poorest neighbourhood is a place where individuals and organizations are resources upon which the rebuilding of an area is possible. The key is to track them and connect them in a way that leverages efficiency. Marginalized people are encouraged to participate in an all-inclusive process towards development. Organizations in the area play a key role and many times in the process they may take up more responsibilities to serve community needs.

We have found Dourgouti to be a rich area in terms of resources. Assets such as the neighbourhood's history, the active local organizations and active citizens have been brought to attention and made known through local research and open call for local participation in the project. Additionally, through the open cultural activities a new network has been created, connecting people and organizations in an entirely new way, working consciously or subconsciously for a common goal which is the area's development. A "third party", a visitor, in this case an artistic company, becomes the catalyst by observing things in a new way and initiating collective projects that break borders within the community and between the neighbourhood and the rest of the city - country - world. These actions potentially promote two main types of social capital in community development: bonding and bridging. Bonding social capital refers to networks of homogeneous groups of people, which tends to produce resources that help individuals to 'get by'. Whereas bridging social capital is concerned with people having access to network(s) across their social divisions, which helps individuals to 'get ahead'.

\subsection{Best Practices}

Below we briefly describe the best practices that we adopted during our interventions in Dourgouti Island Hotel Project for maximizing the potential of our programme:

\section{Respect for Neighbourhood}

Field research and contact with locals organized by Ohi
Pezoume took place for a period of 6 months before the first event of project. The trust established in this period was essential for the planning and the implementation of the collective processes. The project's participatory character where the locals are the co-organizers of events added to the fact that meetings were held in public spaces and made more and more people feel part of all that was happening.

The voluntary basis of the activities resulting in economic profit from local companies - as a result of Dourgouti becoming a destination of visitors - contributed to quickly establishing friendships. The Urban Dig Project creates voluntary research groups and research activities, considering as "profit" the collection of the hidden local cultural capital and the relationships and partnerships formed during the research process.

\section{Network}

Ohi Pezoume was not only introduced to local network but created an entirely new network bringing in contact again neighbouring organizations and establishing stronger bonds in the community. Local school students, artists, organizations and authorities would sit on the same table to discuss, some for the first time, everyone contributing and possibly giving access to each one's own network.

Because of network's collaboration in the project, new people coming in contact or entering this network would instantly have access to new possibilities, an opportunity not so easily granted before the project. Local sports' club past president was interviewed by national television in a reporting of the project. Club's history was also presented in an arts convention in Sofia, Bulgaria. Local artists could use the facilities of neighbouring prestigious Onassis Cultural Center for rehearsals.

\section{Communication}

The Urban Dig Project uses local, simple, language to communicate invitations and events to local residents. Dissemination is heavily based on physical presence. With all volunteer research groups operating mainly in public space and with most research methods being extravert and fun to attend for all, every day of research is a day for making the local Urban Dig Project community larger and more diverse.

\section{Do It Yourself}

The organizers' attendance in all field-work and the feeling of inclusion in the Urban Dig Project's collective processes, created a safe environment for people to widen their comfort zones when it came to collaborations and to work together with people that they would otherwise not work with. Local community groups would end up working with geographers from the University, students from three Universities would present their ideas for bottom-up development and management of the cultural capital of the neighbourhood to the residents and get their 
feedback, innovative artists became friends with neighbours, some workshops and projects involving the neighbourhood required the hosting or the collaboration of prestigious nearby cultural centers and hotels so as to create a link.

Organizers succeeded in temporarily "reclaiming" empty local shops with the help of the municipality. Empty shops were transformed to exhibition venues. Local companies and organizations were attracted by the project and also contributed to hosting the events e.g. The local senior citizens' friendship club offered their space to Dourgouti Oral History Group, Panteion University offered its sports facilities to performers for rehearsals, Hotel Athenaeum Intercontinental offered a conference room for a meeting between the neighbourhood and three university courses producing research and proposal for the development of the area, the local tavern "Vassilis" hosted the local "office" of the project throughout the project etc.

\section{Results}

\subsection{Citizens' Life Improvement and Wellbeing}

The project started in August 2014 and finished with a site-specific performance on the streets on the neighbourhood in October 2015. Sixty-seven groups /institutions /companies ranging from the local house of the elderly and a student band to the municipality of Athens have been collaborators in our events. Six hundred and thirty people in total have collaborated (either through these groups or as individuals) including international artists and scholars from France, Australia, the UK, Austria and Germany, scientists, university students, secondary and primary education students, teachers, professors and many residents. More than four thousand spectators have participated in more than ninety days of local events. Examples of impact of the program include:

- $\quad$ Creating engagement of ages spanning in 15-80. About half of them being locally based and the rest coming from other places of Athens and the world (61\% female / 39\% male)

- Organizing free cultural workshops in the neighbourhood led by Greek and International performers and institutions.

- Instigating not-for-profit cross-sectoral collaborations on local cultural research. Four partnerships between the community and Academic and Cultural foundations as well as groups related to live and digital tours in Athens continue to thrive. One partnership between a historian and a resident has resulted in a documentary about the area.

- Creating interest for Dourgouti by the Media, Tech and Sport sector, Universities, other neighbourhoods, the European Cultural Foundation, the Municipality, historians and Foundations. The team and its local partners have been invited to present Dourgouti Case in more than 23 workshops and conferences in Greece and abroad.

- Creating international mobility of Greek artists in seven world destinations

- Creating international mobility to Dourgouti from Austria, France, Australia, England.

- Providing two students with material for their University dissertations (BSc. and $\mathrm{PhD}$ ) related to Dourgouti.

- Supporting 300 student reports focused in Dourgouti neighbourhood coming from 6 University courses.

- Activating locations within the neighbourhood that were no longer visited (public squares or closed shops, etc.).

- Mapping the cultural capital and community interests to be given back to the community along with related digital cultural management and educational tools.

- Organizing the participation of local primary schools in conferences in Greece (e.g. conference of the Greek Network for Children's Rights) and the participation of a local high school in a festival abroad (AltoFest in Napoli).

- Contributing to local capacity development through workshops and meetings for knowledge sharing. Based on statistics, most participants chose to offer a much wider variety of skills in the project than what they introduced themselves with.

- Supporting local participants of the program to curate their findings about the area into libretti for a music performance celebrating Dourgouti produced by the Onassis Foundation Cultural Center that is based nearby.

- $\quad$ Supporting the creation and the operation of a local Oral History Group that still exists.

- $\quad$ Reclaiming "Dourgouti" as the name of the area, forgotten for years.

Residents now have at their disposal the total archive and methodology produced by the collective research on the local cultural capital. The following curated deliverables are widely available:

- A digital tour in the community and its historical / architectural secrets by Clio Muse

- A website with maps on the neighbourhood's history, art and sensory high and low spots (spots that people prefer or detest during a series of sensory mapping walks)

- Articles about Dourgouti in a number of digital publications including the Social Atlas of Athens.

- Videos of all the in-situ performances inspired by Dourgouti's stories

- The oral history archive produced by the Oral History Group created for and running parallel to 
Dourgouti Island Hotel Project. The local Oral History Group was formed by 40 volunteers who received training on how to conduct and properly register and archive interviews. Participants were divided in different groups according to areas of interest and conducted interviews with Dourgouti residents. Videos and photo material were presented back to the neighbourhood in ongoing events. Many locals contacted Oral History Group to offer information, participate in group or just express gratitude. Interviews from the local Oral History group offered the basis for a common imaginary and identity. Also collaboration of people created conditions of dialogue and coexistence.

Residents can also have access to the academic papers produced for their neighbourhood. These papers, containing scientific observations about the area, the residents' testimonies and remarks and proposals for development of the area, were presented to the residents in an event co-organized by students of the three Universities involved. Some of these University students who volunteered to further participate in running the Urban Dig Project program in Dourgouti (e.g. through curating an exhibition or managing small events etc.) had the opportunity to receive some work experience in their field of studies, before even graduating, and therefore be in better position to pursue a relative carrier.

During the cultural activities people reoccupied public spaces or the "lifeword" [3], usually left unattended, giving a new meaning to human relationships and their environment. Open cultural events in public spaces brought about interaction of people from different backgrounds. Some of the participants or visitors in the festival were migrants that have been living in this multicultural neighbourhood for years, but away from public spaces such as the local park. As a result, a new communication field is created, setting conditions where people can accept the other, where mistrust can dissolve and a new collective imaginary can be established. As the project was becoming known by word of mouth and social media, many current or older neighbourhood the local interest grew: Residents offered information and personal material about the neighbourhood, offered their time and energy as participants of the events and even organized some of them, such as concerts with songs inspired by neighbourhood myths, history walks, athletic events inspired by the local stories etc. At the same time local tavernas, gyms and clubs offered their space to the program, provided discounts to the program's community etc. Local authorities, showed interest to a "forgotten", according to residents, neighbourhood by cleaning certain areas or replacing broken lights, supported small events of the program and helped communicate the program through local, national and international channels.

\subsection{Active Citizenship}

Active citizenship shall promote common good rather than focusing on the needs of certain individuals or groups in society. It can be as straightforward as helping a neighbour. In the Dourgouti Island Project, neighbours' interaction is frequent and the involvement of local residents plays a key role in the project. As derived from the interviews of the participants, each one has his/her own reason for contributing, and feels he/she belongs to this project in different ways.

The collaboration with Professor Martin Phillips from Leicester University allowed locals to talk about the neighbourhood's problems through games as 'Dourgoutopoly'. The game proved an efficient yet "safe" way for residents and local clubs to discuss local politics. A local committee was soon formed, a tool for locals to converse and to address their needs, such as the cleaning of a certain area, a demand in the minds of many that surfaced during discussions, to the municipal authorities. Meetings with municipal authorities have already produced some results such as lowering the rent for local shops, given that the municipality of Athens owns these shops.

Finally, the local committee has access to the whole archive collected through the program. The archive includes collection of historical photos, video interviews with local residents, university papers, map of neighbourhood with key historical places and events, collection of other local archives etc. The archive was handed back to the neighbourhood during an open workshop towards the cultural and community groups of Dourgouti, including this newly formed local committee. Some non-resident participants of the program have also continued engagement with the neighbourhood. One example is a visitor of one of the program's festivals who is now offering English classes to a local youth club.

\section{Discussion}

\subsection{Culture}

The Urban Dig Project puts in action a series of cultural activities. In our approach we were fully aware of the multifaceted aspects of what "culture" entails. Culture is associated with the term civilization and civilization with the city, urbanization and organization of social life. Two historical facts play important role in this aspect: the rise of the nation state and the development of cultural traditions of societies with political organization [4]. According to Giannaras [5] civilization (politismos) means the outcome or product of the city (polis), is related with the term citizen (politis) and is defined as "way of living".

\footnotetext{
1 A community game based on the famous game 'Monopoly' https://www2.le.ac.uk/departments/geography/redundant-content/researc h/old-research-folder/projects/ConCom/glossopoly
} 
Tylor [6] defines culture as "that complex whole which includes knowledge, beliefs, arts, morals, law, customs, and any other capabilities and habits acquired by [a human] as a member of society.” Linton [7] adds to his definition the element of transmitting one's attitude and behaviour to descendants.

Steward [8] in his work "Theory of Culture Change" underlines the importance of the environment in shaping societies, explaining that societies adjust according to local conditions. Societies adopt "certain cultural types of behaviour" for their survival [4]. The factors that define this behaviour are political and economic and constitute the "culture core" of a society [4].

Geetz [9] includes in his definition of culture everyday human activities that generate "meaning". For Geertz culture and social structure are sides of the same phenomenon. According to Sahlins [10] the cultural characteristics of the environment create a symbolic system that defines the needs and desires of a human being. Therefore it is not the interests that affect choices in economy and production but the "cultural conditions" or “cultural codes” [11].

Marx [12] explains that material reality (base), which is the means of production and the relations of production, is interpreted through society's relationships and ideas (superstructure). These interpretation schemes (beliefs, perceptions, customs and attitudes are formed by those who have the (ideological) power. Those who work in the means of productions (proletarians) cannot understand the reason behind historical evolution and that is because this process is refracted through the deforming lenses of ideological systems. As a result proletarians fail to understand the society in which they live and the effort to change the society is much greater.

According to Thorsby [13] when a group that expresses itself through culture, acquires distinct identity that differentiates its members from the members of other teams.

Foucault [14] uses the terms discourse to underline the direct relation between knowledge and power. An individual is directed and influenced by the language of “experts” such as politicians, judges etc. without being able to develop his/her own critical thought. According to Foucault language creates hierarchical structures.

The cultural content and the impacts of the Urban Dig Project for Neighbourhoods can be interpreted through all these distinctive lenses of "culture" described above. For some, it could mean that the citizens gained more power through self-management and 'do-it-yourself' practices; for others that the local community bonded as a single entity with a strong social capital; and for others that the residents will never succeed in having a meaningful participatory action in any decision-making of the municipal authorities and all those actions from the bottom-up do not really contain any high level of power.

No matter what socio-political stance one adopts in relation to culture, there is no doubt that the particular programme led into local development.

\subsection{Local Development}

Ohi Pezoume Performing Arts Company begins local research and develops cultural activities with an artistic goal in mind: to gather information for the script of a final theatre play on the neighbourhood streets. Cultural activities can act as a lever for local development. According to Babiniotis [15] development is the improvement of economic indexes (of a country) with key element the increase of production. Development here is not meant strictly by economic growth. According to the United Nations Development Program [16] "Human development $(\ldots)$ is about expanding the richness of human life, rather than simply the richness of the economy in which human beings live. It is an approach that is focused on people and their opportunities and choices.”

According to Leandros [17] the great economists who founded the science of Political Economy have placed emphasis and importance on the factors that determine the wellbeing of human societies. Such factors are: the way the state is organized, education, culture and political conditions. In the late $19^{\text {th }}$ century there is a significant shift made by the economists of the classical school: from how goods are produced to how the financial result is distributed in order to achieve the maximum possible benefit for the society [18].

Mill's proposals [19] for organizing production in a society pay great attention to the way institutions, laws and practices, affect the mental state, the moral and emotional wellbeing of the individuals. Also these proposals are not rigid but take into account the ever-changing socio-political environment. In addition, Mill [19] suggests the maximum benefit for the society, but makes distinction by placing more value in the "higher" delights, namely the aesthetic, the mental and the moral.

Marshall's book "Principles of Economics" [20] marks a major change in the perspective of economic science and consolidates the neoclassical approach. The subject of study is human behavior in the attempt to meet needs with limited resources. In this calculation of maximum usefulness, the spiritual and emotional needs of human beings are not are taken into account [17] while technology, market institutions and people's preferences are taken for granted.

Mill [19] focuses on individual freedom and considers it inviolable. The neoclassical approach focuses on the individual, but does not take under consideration the wider socio-economic context. The person is considered a being that acts rationally and factors that influence people's choices, such as social relationships and "cultural elements" [21] are ignored (p.185). This view largely shapes modern perceptions about the consuming way of life as well as the concept of development. Economic 
theory was isolated from social sciences and now mathematics is used as the main tool for understanding and interpreting the economy. The Gross National Product, i.e. the market value of all finished goods and services produced in an economy during a certain period, is the index used extensively to describe economic enlargement.

However economic growth as a GDP growth should not always be considered a positive event [17]. The environmental and social impacts of human actions may degrade people's standard of living and even slow down the development process.

During the last decades however, economists have begun to recognize the wider social and environmental cost of the economy with the sole aim of growing that is GDP growth. "The Limits of Growth" (1972) by Meadows [22] etc. is a point of reference, arguing that an economy based on limited resources can not exponentially increase.

The Brundtland Report ("Our Common Future", 1987) presented by then Swedish Prime Minister Gro Harlem Brundtland showed the serious environmental impact of development activity and proposed pioneering and realistic ways to tackle the problems. The report makes it imperative for individuals and businesses to take responsibility and encourages non-governmental participation encourages the participation of non-governmental organizations and civil society groups in the democratic decision-making process. Economic growth as policy is not rejected but its content is redefined.

The Urban Dig Project for Neighbourhoods aimed to and led to local development. According to Florida [23] one of the most popular myths is that "geography is dead". He suggests that local economy is based on the concentration of real people in real places and that "creative people" such as artists, opinion makers and everyone who develops creative skills are the driving force behind the development. This is exactly what happened in the local community of Dourgouti. Diverse groups of society such as local residents, local and state stakeholders, University students and professors, commercial groups, visitors, were bonded through the Urban Dig Project activities and initiatives. Relationships of trust were created among varied individuals while new networks were created and established. For Putnam [24] social capital is defined as trust, norms, and networks that facilitate cooperation and mutual benefits, which operates mainly at the community level. Social capital is a by-product of social interactions that makes subsequent collaborative work easier and more likely. Synergies of people from different backgrounds and with different roles gathered in Dourgouti with a common purpose: to develop their relations further which potentially led into the development of their social, cultural and economic fabric through new and ongoing networks. Putnam [24] identifies that by building up social capital, strong social institutions can be established, as a result, that can bring about economic growth and effective government.
He also suggests that social capital is a resource to communities that can be benefited to their community members regardless of whether they participant or not. In this sense, there are two types of members here, direct and indirect participants. Direct participants often refer to people who take part in the Urban Dig Project activities, whereas indirect participants include spectators, visitors (having a sense of team identity), or volunteers (a form of social participation or civic engagement).

Consequently, engaging with the Urban Dig Project activities individuals and groups develop trustworthy friendships, trust and social commitment, which contribute to developed social capital and social cohesion, and then social cohesion contributes to economic development and sustainability for societies [24].

\section{Conclusions}

A cultural intervention like Dourgouti Island Hotel Project through cultural actions brings to surface and creates a network of "creative" people. Residents can participate in different groups, use communication and other tools and with the basis of a common history and identity can work towards a more sustainable development for the neighbourhood. Artists through cultural activities can work as a catalyst to this development.

The collective good, according to narrations of local residents, cannot be expressed by existing authorities. Historical research, participatory initiatives and collective action give new meaning to human relationships, and encourage locals to use and reclaim existing resources. Today's dominance of positivism emphasizes material objects and gives importance to quantity. On the contrary, culture by nature gives emphasis to quality, encouraging people to think, to give new meanings or even change existing structures.

Greece does not have a significant industrial sector that could contribute significantly to its economic development. Culture is the symbolic capital that today supports its social and economic condition. In an era of isolation, characterized from a focus on personal interest, culture shows a way of coexistence and reconciliation. These can both elevate the quality of life and create the basis of a new economy.

\section{REFERENCES}

[1] J. McNight, A Basic Guide to ABCD Community Organizing. Available online: http://www.abcdinstitute.org/docs/A\%20Basic\%20Guide\% 20to\%20ABCD\%20Community\%20Organizing-1.pdf. (Accessed 2/5/2015)

[2] T. Fuller, D. Guy, C. Fletch, Asset Mapping, A Handbook, 
Volunteer Canada. Available online: http://volunteer.ca/content/asset-mapping-handbook (Accessed 2/5/2015).

[3] J. Habermas, The Structural Transformation of the Public Sphere: An Inquiry into a Category of Bourgeois Society, The MIT Press, Cambridge, 1991.

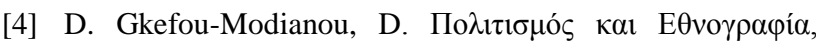

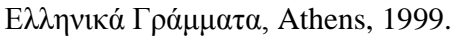

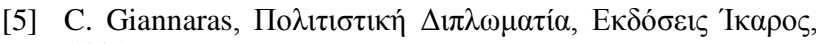
2001.

[6] E.B. Tylor, Sir Primitive Culture: Researches in the Development of Mythology, Philosophy, Religion, Art and Custom, Gloucester: A.A.A, 1958 (1871).

[7] R. Linton, “Acculturation “, in Acculturation in Seven Indian Tribes, Gloucester, Massachusetts, Peter Smith, R. 1940.

[8] J. Steward, "Theory of Culture Change", Urbana, Illinois, University of Illinois Press, 1968.

[9] C. Geertz, The interpretation of Cultures: selected essays, New York, Basic Books, 1973.

[10] M. Sahlins, Culture and practical reason, Chicago and London, The University of Chicago Press, 1976.

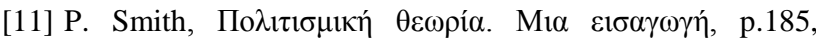
Kрıтıќ, Athens, 2006.

[12] K. Marx, «The fetishism of commodities and the secret thereof». $\Sigma \tau_{0}$ Janet L. Dolgin, David S. Kemnitzer $\kappa \alpha$ i David M. Schneider (ed) Symbolic Anthropology A reader in the Study of Symbols and Meanings, New York, Columbia University Press, 1977.
[13] D. Thorsby, D., Economics and Culture, Cambridge University Press, 2001.

[14] M. Foucault, Politics, Philosophy, Culture: Interviews and Other writings, 1977-1984 (Lawrence D. Krizman), New York, Routledge, 1988.

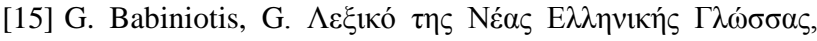

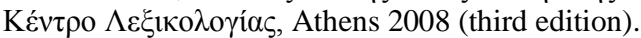

[16] United Nations Development Program, Human Development Reports, Available online: http://hdr.undp.org/en/humandev (Accessed 29/5/2015), p.1.

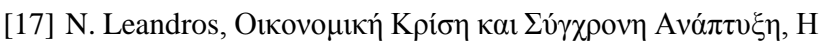

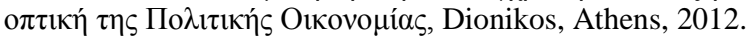

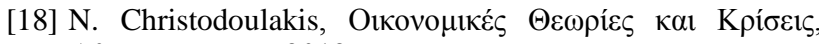

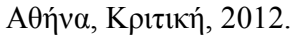

[19] S. Mill, Essays on Some Unsettled Questions in Political Economy, 1844 online at: https://www.marxists.org/reference/archive/mill-johnstuart/ 1844/unsettled.htm\#ESSAY_V (Accessed 29/5/2015)

[20] A. Marshall, A. Principles of Economics, Overstone, Bristol, 1920.

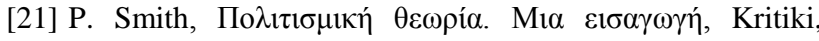
Athina, 2006.

[22] D.H. Meadows, D.H, J. Randers and III W.W. Behrens, The Limits to Growth, Universe Books, New York, 1972.

[23] R. Florida, Cities and the creative class, Routledge, London, 2004.

[24] R. D. Putnam, Bowling alone: The collapse and revival of American community, Simon and Schuster, 2000. 